\title{
FAP Flap: A Volte Face to Familial Adenomatous Polyposis
}

\author{
Ashish Gupta
}

Received: 23 February 2011 /Accepted: 6 October 2011 /Published online: 19 October 2011

(C) Association of Surgeons of India 2011

This is regarding a well-worded case report, 'A rare case of FAP in Kashmir Valley' published online in the Indian Journal of Surgery on 2 February 2011. It brings back candid memories when such acronyms were used in clinical teachings and the reprimand that ensued. Well that was old school! Acronyms have become the flavour of the day with examiners as well as publishers. But these acronyms hold different meaning for people of surgical and its allied specialties.

FAP stands for facial artery perforator flap to our plastic and reconstructive surgery colleagues [1]. It entails raising the nasolabial skin fold based on the perforating branches of the facial artery to cover the defects of the lower eyelid, lateral cheek and perioral region. This area is popularly known as the jowl area to the cosmetic surgeon.
The FAP flap can be raised from the inferior border of the mandible to the ala of the nose on any of the six odd perforators arising along the course of the facial artery and rotated as a propeller (of a ship/airplane) to be inset in the area of the defect. The dissection is carried out in a plane above that of the muscles of facial expression. FAP flap can be as large as $5 \times 5 \mathrm{~cm}$ and the donor defect can be closed primarily [2].

\section{References}

1. Hofer SO, Mureau MA (2010) Pedicled perforator flaps in the head and neck. Clin Plastic Surg 37:627-640

2. Hofer SO, Posch NA, Smit X (2005) The facial artery perforator flap for reconstruction of perioral defects. Plast Reconstr Surg 115 (4):996-1003

A. Gupta $(\bowtie)$

Department of Plastic Surgery \& Burns,

Dayanand Medical College \& Hospital, Ludhiana, India

e-mail: docashish2001@gmail.com 